\title{
Victorian fire weather trends and variability
}

\author{
S. Harris ${ }^{a, b^{*}}, \underline{\text { G. Mills }}^{\mathrm{a}}$, and T. Brown ${ }^{\mathrm{c}}$ \\ ${ }^{a}$ School of Earth, Atmosphere and Environment, Monash University, Clayton, Victoria, Australia, \\ ${ }^{b}$ Fire and Emergency Management, Country Fire Authority, East Burwood, Victoria, Australia, \\ ${ }^{c}$ Division of Atmospheric Science, Desert Research Institute, Reno, NV, USA. \\ Email: gam4582@gmail.com
}

\begin{abstract}
Information on the trends and variability of fire weather indices and weather variables has a wide variety of applications to the development of systems to assist fire management activities including prevention, preparedness, response and recovery. Such information based on the observation record is constrained to the few observation sites that have sufficiently long record, while climate model produced climate datasets tend to lack the spatial resolution required by fire agencies. A bias-corrected, downscaled reanalysis climatology over Victoria (VicClim) ameliorates these limitations.
\end{abstract}

Using the latest version of the VicClim gridded fire weather dataset, the spatial ( $4 \mathrm{~km}$ grid) and temporal (hourly) variability of fire weather for Victoria for 1972-2017 is explored, with McArthur's Forest Fire Danger Index (FFDI) representing fire weather. Various metrics are calculated: the $99^{\text {th }}$ percentile of FFDI, probability of days with an FFDI over defined fire danger thresholds (High, Very High and Severe), and the decadal differences in these thresholds for all grid points. We also determine the Victorian averaged diurnal, seasonal and annual daily maximum FFDI, annual $90^{\text {th }}$ percentile FFDI, and cumulative FFDI. The annual number of days with an FFDI above the fire danger thresholds are calculated, and finally we determine the variability of fire season length (FFDI days $>25$ ) and changes to the start and end of the fire season.

It is shown that there is a significant positive relationship between fire activity (annual number of fires, total area burned) and annual accumulated FFDI. There is large spatial variability across Victoria in extreme $\left(99^{\text {th }}\right.$ percentile) FFDI with the highest values in the north west and the lowest values in the Alpine region. The variability also differs across seasons with the biggest spatial contrasts in FFDI occurring in spring and summer. There is broad interdecadal variability in the $90^{\text {th }}$ percentile FFDI averaged across Victoria through the study period, with a neutral period through the 1970s to the early 1980 s, a negative anomaly from the mid 1980s to the end of the 1990s, and a positive anomaly from the early 2000s through to 2017, with a short- lived but strong negative anomaly in 2010-11. The broad interdecadal variability is also evident when daily maximum FFDI is separated by seasons for summer, autumn and spring but the upward trend in the most recent decades found in those seasons is not evident in the winter. Diurnal differences in trend and variability were observed with greater year-to-year variability and an upward trend since the early 2000s in summer 3pm and 9pm FFDI values but less variability and no upward trend in the summer $3 \mathrm{am}$ and $9 \mathrm{am}$ FFDI.

There are spatial variations in decadal changes in the number of days with an FFDI over 25 with some decades having one half of the state with above average number of days and the other half having below average number of days. Overall, the findings correspond with the Victoria averaged time series of below average number of days for each threshold in the 1990s and an above average number of days for each threshold in the 2000s. We find that the number of days with an FFDI over 25 for over $10 \%$ or more of the state each year (July to June) from 1972-73 to 2001-02 is on average 66 days. Since 200203 through to 2016-17 the average has increased to 94 days per year. There are only six fire seasons that have over 100 days with an FFDI $>25$ and these all occur between 2002-03 and 2016-17.

Finally, when the first and last day of the season with an FFDI of 25 is compared with a selected calendar date ( $1^{\text {st }}$ Sep and $1^{\text {st }}$ May, respectively) we find that from 1972-73 through to 2001-02 there were five occurrences of the fire season starting earlier, whereas since 2002-03 there have been 10 years that have had an earlier start. This trend to an earlier start to the fire season is also supported by an increase in the number of days with an FFDI over 25 in the transition month at the beginning of the season (September) being found. There is no increase evident in the number of days from the end date of the season or in the transition month at the end of the season (April).

The results from this study provide hitherto unavailable understanding of regional variability and trends in fire weather over Victoria for fire agency personnel to incorporate in the long term planning of resource allocation and landscape management.

Keywords: Fire weather, trends, variability 


\section{INTRODUCTION}

Information on the trends and variability of fire weather indices has a wide variety of applications that include development of systems to assist fire management activities including prevention, preparedness, response, and recovery. Such information based on the observation record is constrained to the few observation sites that have sufficiently long record, while climate model produced climate datasets tend to lack the spatial and temporal resolution required by fire agencies. A new and unique high spatial $(4 \times 4 \mathrm{~km})$ and temporal (1-hour) resolution bias-corrected homogenous 46-year gridded fire weather dataset developed for Victoria (Brown et al 2016) makes it possible to identify the trends and variability of FFDI. In this study we characterise the variability and trends of fire weather in Victoria, Australia using the latest version (19722017) of the gridded fire weather dataset - VicClim Version 3. We initially show the relationship between FFDI and fire activity in Victoria, then explore the decadal, annual, seasonal, and diurnal variability of fire weather and how the fire season length is changing across the Victorian landscape. The results from this study provide hitherto unavailable understanding of regional variability and trends in fire weather over Victoria for fire agency personnel to incorporate in the long term planning of resource allocation and landscape management.

\section{DATA}

\subsection{Fire Activity Data}

Numbers of fires and areas burned per year were extracted from the Department of Environment, Land, Water and Planning (DELWP) ignition dataset. Planned burns were excluded from the analyses. The total number of fires and area burned for Jul-Jun for the 1972-73 to 2013-14 fire seasons were calculated. The natural logarithm of area burned was calculated as the data are skewed by a number of years with large areas burned.

\section{$2.2 \quad$ FFDI data}

The VicClim dataset was developed for Victoria using the Weather and Research Forecasting (WRF) model (Brown et al 2016) in a decade-long partnership project between the Desert Research Institute in Nevada, USA, DELWP and Monash University. This dataset has a spatial resolution of $4 \times 4 \mathrm{~km}$ and an hourly temporal resolution for surface parameters FFDI, temperature, relative humidity, wind speed and wind direction, extending from 1972 to 2017. This dataset also includes daily Keetch-Byram Drought Index (KBDI) and drought factor (DF). The KBDI and DF were calculated using the VicClim temperature values combined with daily precipitation values from the Australia Water Availability Dataset (AWAP) (see Jones et al 2009). This VicClim dataset replaces Version 2 (see Brown et al 2016). Changes and improvements to VicClim Version 3 include:

1. Dataset extended through December 2017 from 1972.

2. Further Quality Control (QC) process for hourly wind - Rather than basing the $80^{\text {th }}-20^{\text {th }}$ percentile threshold on all hourly values of wind (as previously), separate thresholds for each hour and each month were used to incorporate diurnal and seasonal variation, together with the application of a simple 1:2:1 hourly time smoothing by month to further minimise outliers.

3. Highest maximum and lowest minimum temperature station matching for temperature QC on hourly AWS data to ensure that these values do not exceed maximum and minimum temperature extremes. This ensures that model values do not exceed an individual station's maximum and minimum temperature extrema.

4. Adaptive Inverse Distance Weighting (IDW) of station location corrections across the grid - rather than use a single distance weighting function across the whole grid, an IDW power level for every station for every hour through the 1972-2016 period based on removing the station and determining the distance weighting power that gave the lowest percent error at that station.

5. Land-sea boundary artefacts - Masked ocean when creating climatology to remove unrealistic interpolation over the ocean.

\subsection{Analysis}

To analyse the relationship between fire activity and FFDI, the data were linearly de-trended to capture only the interannual relationship rather than the effects of congruent trends. Pearson's correlation coefficient (r) was then calculated with statistical significance assumed at the $95 \%$ confidence interval $(\mathrm{p}<0.05)$.

To diagnose the spatial and temporal variability of FFDI various metrics were calculated: the $90^{\text {th }}$ and $99^{\text {th }}$ percentiles of FFDI, the decadal differences in these thresholds for all grid points, and fire season cumulative 
FFDI. We also determine the Victorian averaged diurnal, seasonal and annual daily maximum $90^{\text {th }}$ percentile FFDI. Further, we calculate the annual number of days with an FFDI over the fire danger threshold (FFDI $>25$ for $10 \%$ of the area) and finally we determine the variability of fire season length and determine changes to the nominal start ( $1^{\text {st }}$ September) and end ( $1^{\text {st }}$ May) of the fire season.

\section{RESULTS}

\subsection{Link between FFDI and fire activity in Victoria}

Timeseries of the Victorian fire activity with FFDI are shown in Figure 1a and b. The correlation coefficient between fire activity and $90^{\text {th }}$ percentile FFDI are for number of fires $r=0.67(\mathrm{p}<0.01, \mathrm{n}=42)$ and for natural logarithm area burned $r=0.79(\mathrm{p}<0.01, \mathrm{n}=42)$. This is a significant relationship in Victoria between fire activity and FFDI. Other studies have also identified a relationship between FFDI and impact (Blanchi et al 2014 and Harris et al 2012).

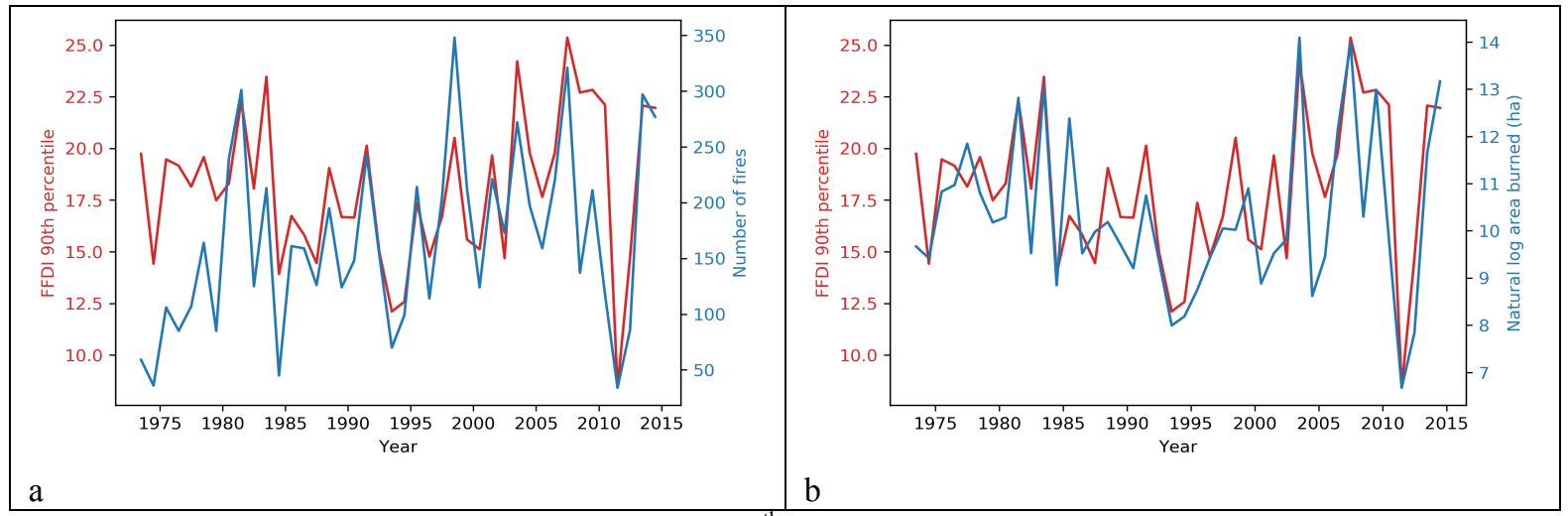

Figure 1. Time series of the annual (July-June) $90^{\text {th }}$ percentile FFDI for Victoria versus Total Number of Fires (TNF) in a, and in b versus natural log of Total Area Burned (TAB, hectares) for the same period.

\subsection{Spatial variability of FFDI by season}

The $99^{\text {th }}$ percentile FFDI values for each season are presented in Figure 2.

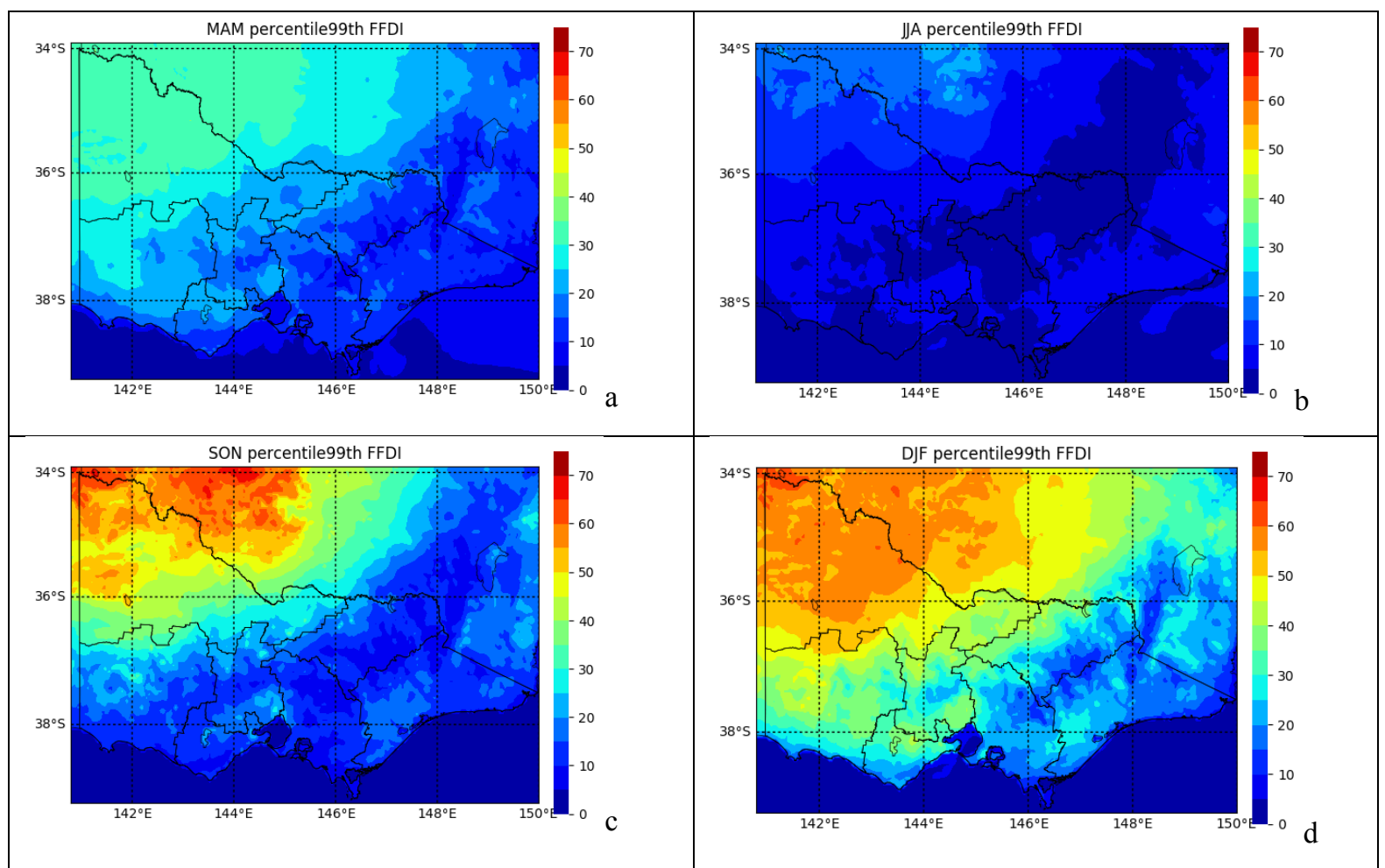

Figure 2. The $99^{\text {th }}$ percentile of FFDI for 1972-2017 for each season - a. March, April, May (MAM), b. June, July, August (JJA), c. September, October, November (SON) and d. December, January, February (DJF) 
Summer (DJF) is the season with the highest FFDI values overall. Spatially the highest FFDI values occur in the northwest of the study area and the lowest values in the Alpine area. The lowest values across the state are found in winter (JJA). Spring (SON) and DJF have the greatest contrast between the east and west of the state with values greater than 30 in the west and lower than 30 in the east, and the values in the northwest and west of the state are higher in spring than in autumn. Many alternative diagnoses, such as probability of exceeding set thresholds (eg Very High FDR), as shown in Figure 3, or number of days above thresholds by year, season, or month, can also be presented as spatial displays.

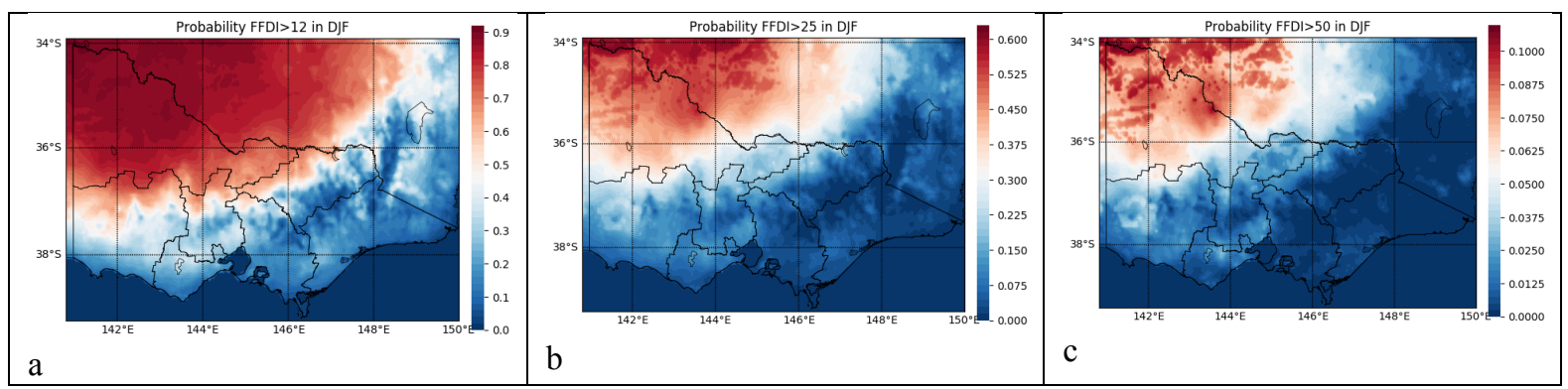

Figure 3. Probability of daily maximum FFDI greater than 12 (a), 25 (b), and 50 (c) in December, January and February, based on data from 1972-2017. Note the different scales for each probability panel.

\subsection{Annual trends and variability}

There is a broad inter-decadal pattern in the annual anomaly in average daily maximum FFDI over the study period (Figure 4a). Through the 1970 s to the early 1980 s there is a period of oscillating years between positive and negative anomalies, followed by an extended negative anomaly from 1984 to 2000. From 2002 until 2017 the FFDI anomaly was positive with the exception of the strong negative anomaly in 2010-11; this 12-month period had very much above average rainfall over all of Victoria except East Gippsland, and for the DJF period most of the state had its highest on record rainfall (Bureau of Meteorology 2018), leading to very low drought factors. Most of the years with high positive anomalies such as 1982-83, 2002-03, 2006-07, and 2008-09 coincided with, or were followed by, years that resulted in active fire seasons (https://www.cfa.vic.gov.au/about/major-fires).

The magnitude of the year-to-year variability between seasons also differs greatly (Figure 4b). The greatest year-to-year variability is in DJF, followed by SON, whereas there is very little year-to-year variability in JJA. All of the seasons, with the exception of JJA, follow the broad inter-decadal patterns found in the annual anomalies, with an upward trend since the early 2000s. Increases in seasonal maxima through MAM and SON, and the increased springtime variability, if sustained, may have consequences for planned burning windows.

There is large year-to-year variability in the Victorian mean 3pm DJF FFDI values compared to the Victorian mean $3 \mathrm{am}$ and 9am DJF FFDI values (Figure 4c). The five-year running mean 3pm and 9pm FFDI follow the broad inter-decadal pattern found in the annual anomalies, but this is not as evident in the 3am and 9am FFDI values. The Victorian 3am and 9am mean DJF FFDI has remained relatively unchanged from 1972-73 to 2016-17, lacking the upward trend found for most other temporal periods. The sharp drop in the cooler and wetter year of 2010-11 is evident for all hours.

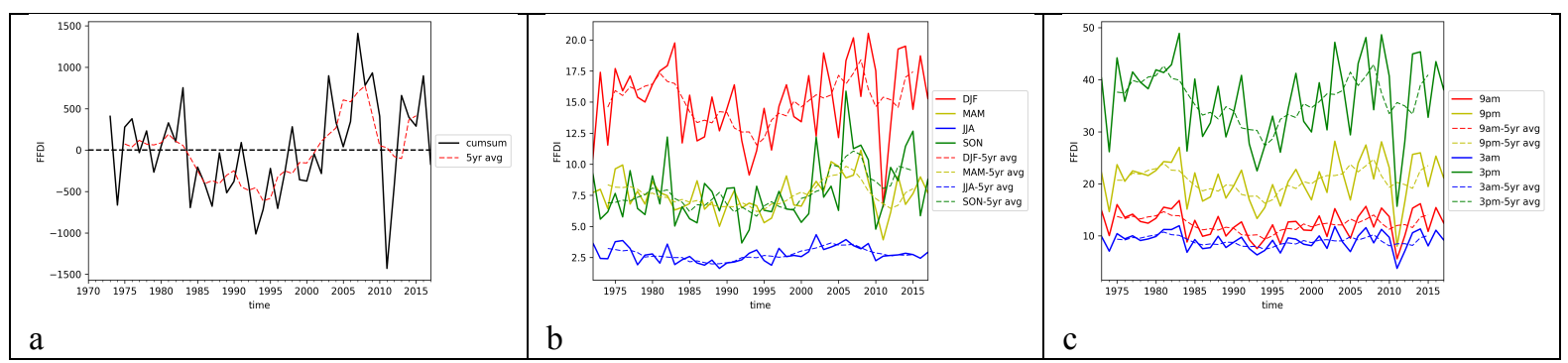

Figure 4. Left (a): the Victorian spatially averaged cumulative mean daily maximum FFDI annual anomaly (July 1972-June 1973 to July 2016-June 2017) and five-year running mean. Middle (b): the seasonal Victorian mean daily maximum FFDI for each year 1972-2017 (except DJF which instead covers 1972-73 to 2016-17) and five-year running mean. Right (c): Victorian mean 3am, 9am, 3pm and 9pm FFDI in December-January-February each year $1972-73$ to $2016-17$ and five-year running mean. 


\subsection{Decadal changes in number of days of 'Very High' FFDI}

The mean number of days per year with an FFDI over 25 for the entire study period (1972-2017) is shown in Figure 5a. There are less than 10 days per year for much of the eastern and southern parts of the state extending up to over 50 in the north west of the state, with lower values along the Alps to the east of Melbourne, and the Central Highlands and Grampians to the west.

The decadal differences from the mean in Figure 5a (Figures 5b-f) show that in the 1970s and 1980s the east of the state was slightly above average, central areas were average, and the north west was slightly below average. In the 1990s (Figure 5d) the very highest alpine areas show above average values, with the northwest below average, and the remaining areas of the state about average. The $2000 \mathrm{~s}$ are well above average for most of the state and the biggest deviation from the mean is again in the north west (Figure 5e). The 2010s (Figure 4f) also show above average conditions, although not to the extent of the 2000s, and many parts of the east were around or only just above average.

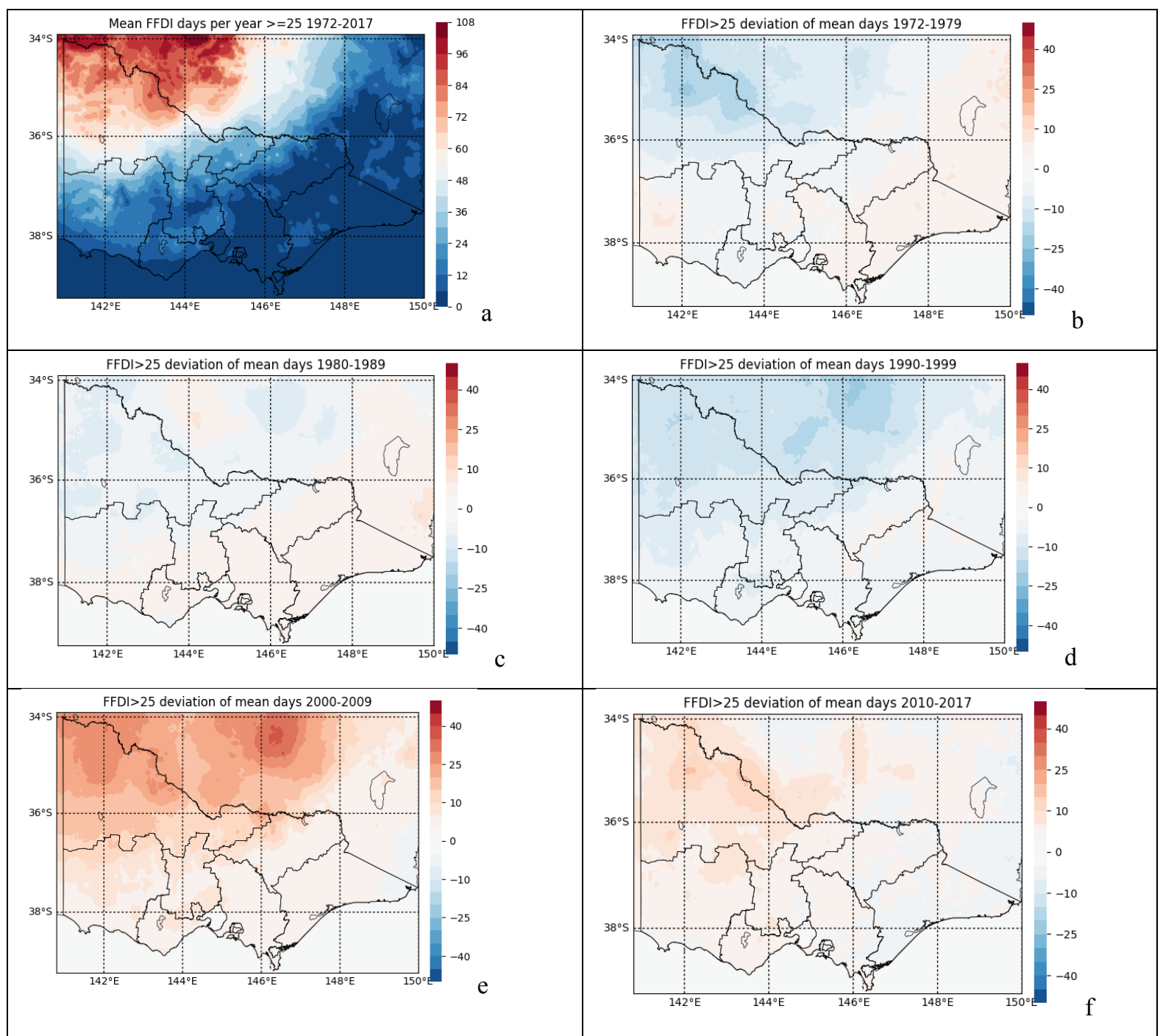

Figure 5. Mean number of days per year with FFDI $>25$ for 1972-2017 (a), and deviation in mean number of days with FFDI >25 per year for 1972-1979 (b), 1980-1989 (c), 1990-1999 (d), 2000-2009 (e), and 20102017 (f), from the mean number of days with FFDI $>25$ per year for 1972-2017.

\subsection{Fire season length trends and variability}

As one measure of fire season variability we calculate the number of days for which $10 \%$ of Victorian gridpoints have FFDI over 25 each year (July to June) to explore the trends and variability in the fire season. We find from 1972-73 to 2001-2002 there is an average 66 days (Figure 6a). However, since 2002-03 through to 2016-17 the average has increased to almost 94 days per year. This suggests that on average there are an additional 28 days with an FFDI over 25 for 2002-03 to 2016-17 compared to 1972-73 to 2001-02. 
There are only six years (July to June) that have over 100 days with an FFDI $>25$ and these all occur between 2002-03 and 2016-17.

The calendar dates often referred to by fire agencies to define the start and the end of the fire season $\left(1^{\text {st }}\right.$ September and $1^{\text {st }}$ May respectively) have been used to determine whether fire seasons are starting earlier or later. Defining the end of the fire season as the last day in the July-June year on which the FFDI exceeds 25, we find that the fire season ends before 1 May on all but five years (Figure 6b). There are no trends evident in the fire season end date. This is also the case when the fire season end date is calculated separately for each region (not shown here).

For the start date of the fire season (first day after July 1 when FFDI $>25$ ) we find that on most occasions the fire season starts later than the calendar start-date of $1^{\text {st }}$ September (Figure 6c). Of the 45 fire seasons analysed there were 15 that had an earlier start. From 1972-73 through to 2001-02 the fire season started earlier on five occasions. However, since 2002-03 there have been 10 years that have had an earlier start. This trend may have serious implications for fire management and prescribed burning windows.
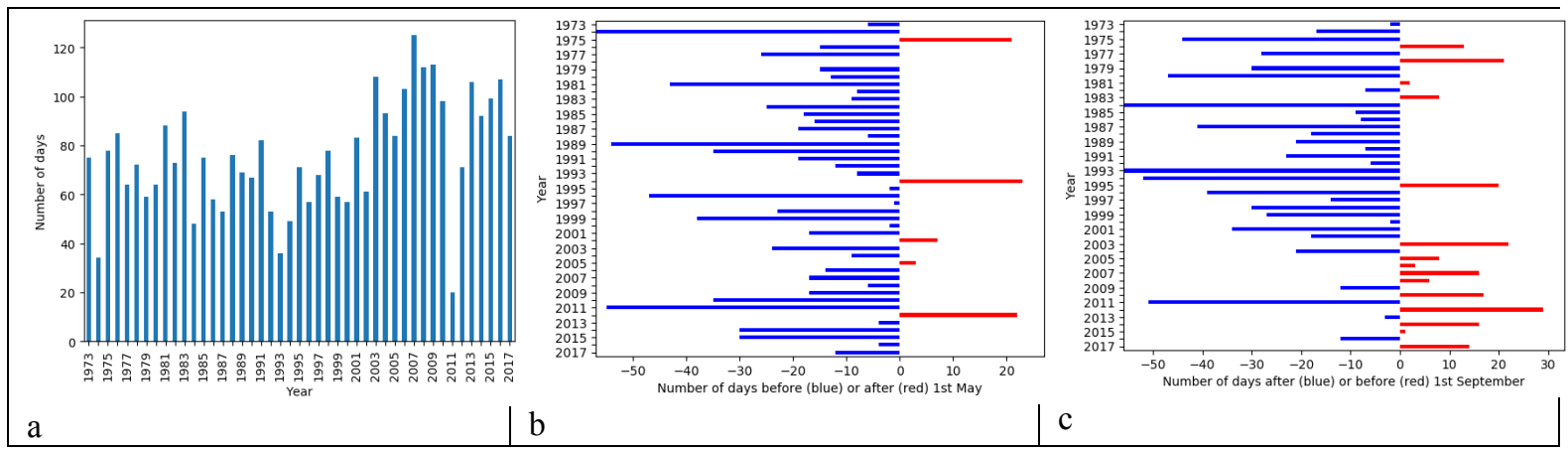

Figure 6. Number of days each year (July to June) that $10 \%$ of Victoria reaches an FFDI greater than 25 for the 12-month periods $1972-1973$ to 2016-2017 (a). The number of days the last day of the year (July to June) to reach FFDI $>25$ (for $10 \%$ of the area) deviates from the fire season end date ( $1^{\text {st }}$ May). The blue indicates the number of days before the $1^{\text {st }}$ May indicating an early finish to the fire season and the red indicates the last day occurred after the $1^{\text {st }}$ of May, indicating a late end to the season (b). The number of days the first day of the year (Jul-Jun) to reach FFDI $>25$ (for $10 \%$ of the area) deviates from the fire season start date $\left(1^{\text {st }}\right.$ Sep). The blue indicates the number of days after the $1^{\text {st }}$ September indicating a late start and the red indicates the first day started before the $1^{\text {st }}$ of September, indicating an early start to the season(c).

Selecting one occurrence above a threshold, as in Figure 6 may not provide a definitive measure of fire season start and end. To provide greater insight, we calculate the number of days with an FFDI over 25 each year for the shoulder months (September and April) (Figure 7). We find that 57\% of the days with $10 \%$ of Victoria with an FFDI over 25 in September occurred in the most recent 17 years (2001-2017) with the remaining $43 \%$ occurring over the 29 years preceding that period. In September the average number of days with FFDI $>25$ averages 1.7 from 1972-2000, and 3.8 from 2001-2017. We do not find any trends in the number of days over 25 in April, with the respective average numbers of days in each period being 2.3 and 2.6. This corresponds with our findings calculating the start and end date deviations that there has been a trend towards an earlier start to the fire season, but little trend in end dates.

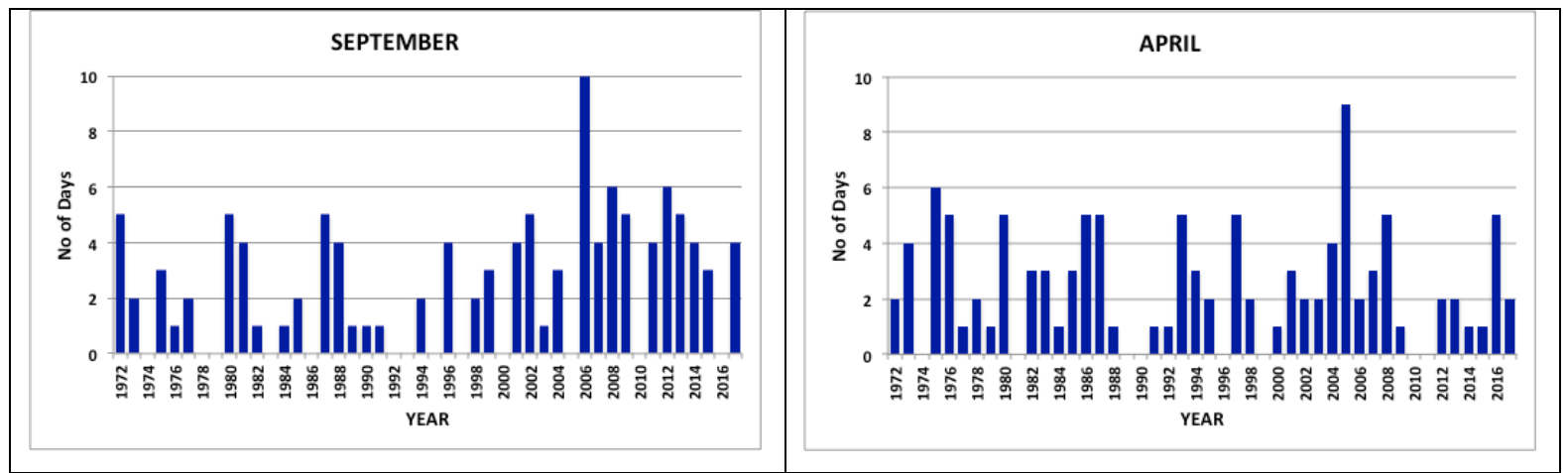

Figure 7. Number of days each year that $10 \%$ of Victoria reaches an FFDI greater than 25 for the fire season shoulder months of September and April 1972-2017. 


\section{SUMMARY AND CONCLUSIONS}

In summary we find there is large spatial variability across Victoria in extreme $\left(99^{\text {th }}\right.$ percentile) FFDI with the highest values in the north west and the lowest values in the Alpine region. The variability also differs across seasons with the biggest spatial contrasts in FFDI occurring in spring and summer. There is broad interdecadal variability in the $90^{\text {th }}$ percentile FFDI averaged across Victoria through the study period, beginning with a neutral period throughout the 1970s to the early 1980 s followed by a negative anomaly from the mid 1980s to the end of the 1990s. This is followed by a positive anomaly from the early $2000 \mathrm{~s}$ through to 2017 with a short-lived but strong negative anomaly in 2010-11. The broad interdecadal variability is also evident when daily maximum FFDI is separated by seasons for summer, autumn, and spring but the upward trend in the most recent decade found in those seasons is not evident in the winter daily maximum values averaged across Victoria. Diurnal differences in trend and variability were observed with the summer 3pm and 9pm FFDI values revealing much greater year-to-year variability and an upward trend since the early 2000s, and the summer 3am and 9am FFDI values less variable and no upward trend.

There are spatial variations in decadal changes in the number of days with an FFDI over 25 with some decades having one half of the state with above average number of days and the other half having below average number of days. Overall, the findings correspond with the Victoria-averaged time series of below average number of days for each threshold in the 1990s and an above average number of days for each threshold in the 2000s.

We find that the number of days with an FFDI over 25 for over $10 \%$ or more of the state each year (July to June) from 1972-73 to 2001-02 is on average 66 days. Since 2002-03 through to 2016-17 the average has increased to 94 days per year. There are only six fire seasons that have over 100 days with an FFDI $>25$ and these all occur between 2002-03 and 2016-17. We also find this change is evident when separated by regions although there is large variability in the extent of this change between the regions.

Finally, when the first and last day of the season with an FFDI of 25 is compared with a selected calendar date $\left(1^{\text {st }}\right.$ Sep and $1^{\text {st }}$ May respectively) we find that from 1972-73 through to 2001-02 there were five occurrences of the fire season starting earlier, whereas since 2002-03 there have been 10 years that have had an earlier start. This trend to an earlier start to the fire season is also supported by an increase in the number of days with an FFDI over 25 in the transition month at the beginning of the season (September) being found. However, there is no increase evident in the number of days from the end date of the season or in the transition month at the end of the season (April).

The results from this study provide hitherto unavailable understanding of regional variability and trends in fire weather over Victoria for fire agency personnel to incorporate in the long term planning of resource allocation and landscape management.

\section{ACKNOWLEDGEMENTS}

The authors thank the Bushfire Natural Hazards CRC for Project Management and Facilitation and the Department of Environment, Land, Water and Planning (DELWP) for funding the creation of the gridded fire weather dataset, VicClim, and this research. We are also grateful for the constructive review of this paper by Mr Andy Ackland of DELWP.

\section{REFERENCES}

Blanchi R., Leonard J., Haynes K., Opie K., James M., de Oliveria F.D., (2014). Environmental circumstances surrounding bushfire fatalities in Australia 1901-2011. Environmental Science and Policy 37, 192-203.

Brown T., Mills G., Harris S., Podnar D., Reinbold H., Fearon M., (2016). A bias corrected WRF mesoscale fire weather dataset for Victoria, Australia 1972-2012. Journal of Southern Hemisphere Earth System Science 66, 281-313.

Bureau of Meteorology 2018, Record rainfall and widespread flooding. http://www.bom.gov.au/climate/enso/history/ln-2010-12/rainfall-flooding.shtml . Accessed 16/08/2018

Harris S.L., Anderson W.M, Kilinc M., Fogarty L., (2012). The relationship between fire behaviour measures and community loss: An exploratory analysis for developing a bushfire severity scale, Natural Hazards [P], 63(2), 391-415. Springer, The Netherlands.

Jones D.A., Wang W., Fawcett R., (2009). High-quality spatial climate data-sets for Australia. Australian Meteorological and Oceanographic Journal 58, 233-248. 